\title{
IT Controlling and IT Productivity
}

\author{
DOI 10.1007/s12599-009-0049-0
}

\section{The Authors}

Prof. Dr. Georg Rainer Hofmann

Hochschule Aschaffenburg

Würzburger Str. 45

63743 Aschaffenburg

Germany

hofmann@fh-aschaffenburg.de

\section{Prof. Dr. Ulrich Frank}

Lehrstuhl für Wirtschaftsinformatik

und Unternehmensmodellierung

Universität Duisburg-Essen

Campus Essen, Gebäude R09

Wirtschaftsinformatik

Universitätsstr. 9

45141 Essen

Germany

ulrich.frank@uni-due.de

This article is also available in German in print and via http://www.wirtschafts informatik.de Hofmann G-R, Frank U (2008) IT-Controlling und IT-Produktivität. WIRTSCHAFTSINFORMATIK. doi: 10.1007/11576-009-0164-z.
Development and use of information technology (IT) is not an end in itself. Its primary purpose is to improve organizational efficiency and quality of managerial decisions. Besides efficiency and effectiveness, IT also enables new business models and innovative products as shown by numerous impressive entrepreneurial success stories. However, IT does not only create remarkable benefits, it may also generate substantial costs and risks. These are caused by the often enormous complexity of IT systems, the contingent development of the IT market and the imponderabilities of running IT projects. From a managerial perspective, it is particularly unsatisfactory that conceptualizing and measuring costs and benefits related to the development, use, and change of IT systems still poses a substantial challenge. To cope with this challenge, it makes sense to implement a specialized organizational function that is aimed at analyzing and promoting the business value of IT, at aligning IT services with business goals and vice versa, and at coordinating the activities of IT and business units. In German-speaking countries, the term "IT-Controlling" is frequently used to represent this function. Despite being derived from the English language, it is unfortunately not used in English-speaking countries. This has somewhat bizarre implications when translating "German" publications on "IT-Controlling" - the more so as there is no English term that directly corresponds to "IT-Controlling". To cope with this unfortunate situation, the papers in this issue make use of "IT controlling" as an umbrella term for "IT performance management", "IT/IS evaluation", etc.

In recent years, the continuing penetration of organizations with IT as well as the growing need to support cross-organizational business processes have contributed to further increase the relevance of managing and evaluating IT from a managerial point of view. The problems caused by heterogeneous, insufficiently integrated IT infrastructures are a further reason to focus on IT controlling. In addition to that, many organizations have to cope with an increasingly volatile and competitive environment. This makes IT architectures which allow for agile and cost efficient adaptations a key success factor. However, planning and realizing an IT architecture will usually involve substantial investment and considerable risks, which makes it essential to thoroughly analyze alternative options with respect to both technological capabilities and business impact. Furthermore, the ever increasing cost awareness of many organizations has underlined the need to align IT services with the core business and, at the same time, to streamline IT operations.

During the last few years, a number of approaches that target these challenges have emerged in business practice. They are aimed at increasing IT transparency and at the introduction of guidelines and policies for delivering IT services. They include generic management concepts, such as IT governance, as well as frameworks like ITIL (IT Infrastructure Library) or COBIT (Control Objectives for Information and related Technologies), which are intended to support the purposeful structuring and coordination of operations performed by IT service units. The demand for IT transparency is reflected, too, by the increasing popularity of specific indicator and performance measurement systems, which promise to provide executives with condensed and simultaneously meaningful information about the business performance of IT systems. Some vendors of software tools that are aimed at supporting the administration of IT service centers have realized this trend. As a consequence, they are striving towards integrating their systems with ERP systems and extending them with so called "dashboards" that provide executives with a clear presentation of information that fits certain decision scenarios.

There is no doubt that IT controlling is a pivotal topic of Business and Information Systems Engineering (BISE; the term used for the German word "Wirtschaftsinforma- 
tik"throughout this publication) and of Information Systems, respectively. This is true in many regards. First of all, promoting the effectiveness and efficiency of developing, maintaining and using IT is an essential research goal. At the same time, dealing with both, technological aspects and their economic evaluation, requires mediating between IT and business, which corresponds to the characteristic cross-disciplinary orientation of our disciplines. Last, but not least, monitoring the economics of IT demands the design of specific information systems, which is at the core of the discipline, too. Against this background, it is surprising that IT controlling does not take a prominent position within current research portfolios - although it was a topic already addressed by a number of publications in the eighties and nineties of last century. We refrain from speculating about possible reasons. However, it seems obvious that the present times offer great opportunities for research on IT controlling. On the one hand, this can be attributed to the demand for corresponding support in business practice. On the other hand, the repository of methods in BISE has been expanded by a number of instruments that are in principle suited to support IT controlling - allowing for a range of attractive new research topics. Therefore, we appreciate the growing awareness that IT controlling has received within BISE research recently. Editing this special issue was motivated by the remarkable relevance of the topic in practice and the re-awakened interest in IT controlling research. It is aimed at providing an overview of the current state of the art, at presenting advanced research results and at inspiring further research in this area.

In their paper, Strecker and Kargl focus on the analysis of integration deficiencies within IT controlling - both in relation to approaches in business practice and to the method repository of BISE - and demonstrate how to address this problem. Maturity models are an important instrument to assess the performance of IT management and to provide an orientation for its further evolution. Jörg Becker, Ralf Knackstedt, and Jens Pöppelbuß introduce a process model that guides the development and evaluation of customized maturity models for IT management. Jan vom Brocke, Christian Sonnenberg, and Alexander Simons introduce an approach to enable the value-driven analysis of IT artifacts. It is adapted to assessing the value provided by serviceoriented architectures (SOA). In their paper, Eva Peggy Sekatzek and Helmut Krcmar address managerial aspects of adapting ERP systems to individual requirements. Illustrated by a case study conducted with the BMW group, they present a performance indicator system to guide a corresponding evaluation of ERP systems. Royers and Meints suggest a multi-dimensional approach, which refers to the Balanced Scorecard. It allows for elaborate assessments of the organizational implementation of IT systems. In a "State of the Art" contribution, Gadatsch gives an overview of pivotal concepts and elucidates selected approaches to IT controlling. Furthermore, he presents his own approach, which is based on a life-cycle model.

We would like to thank the authors of the included papers for their distinguished work. We also thank those authors whose submissions were not accepted for their commitment. Furthermore, we are grateful to the reviewers for their thorough and sophisticated evaluations. We wish you will find reading the papers interesting and inspiring.

Ulrich Frank

Georg Rainer Hofmann 